See Article page XXX.

\section{Commentary: Oral anticoagulants in bioprosthetic valves: Time to adapt}

\section{Hans-Joachim Schäfers, MD}

Vitamin K antagonists (VKAs) have been the mainstay of anticoagulation therapy after valve replacement, including bioprosthetic valves. ${ }^{1}$ Because the evidence for the need for VKA-based anticoagulation therapy in patients with bioprosthesis and sinus rhythm has been soft, guidelines have changed to recommending aspirin as routine treatment for this scenario. ${ }^{2,3}$

During the past 10 years, direct oral anticoagulants (DOACs) have become the preferred treatment for patients with atrial fibrillation without valve replacement, at least in the case that renal function is not impaired. Patients with bioprosthetic valves will generally require anticoagulation medications if atrial fibrillation is present. Guidelines still recommend VKAs for this scenario. In view of the low incidence of thromboembolic complications related to bioprosthesis with normal rhythm, it appears reasonable to assume that the principles of anticoagulation used in atrial fibrillation can also be applied in the presence of bioprosthesis.

In fact, a number of studies have compared safety and efficacy of DOACs with VAKs, summarized in a meta-analysis. ${ }^{4}$ Compared with VKAs, DOACs appear to decrease the incidence of bleeding events, whereas embolic events and survival were similar. These results emphasize that the general management principles of atrial fibrillation also apply to patients with bioprosthetic valves.

A caveat remains. DOACs can accumulate in the presence of impaired renal function, and this can and will lead to an increase of hemorrhagic complications if drug dosage

\footnotetext{
From the Department of Thoracic and Cardiovascular Surgery, Saarland University Medical Center, Homburg/Saar, Germany.

Disclosures: The author reported no conflicts of interest.

The Journal policy requires editors and reviewers to disclose conflicts of interest and to decline handling or reviewing manuscripts for which they may have a conflict of interest. The editors and reviewers of this article have no conflicts of interest.

Received for publication July 27,2021 ; revisions received July 27,2021 ; accepted for publication July 28, 2021.

Address for reprints: Hans-Joachim Schäfers, MD, Department of Thoracic and Cardiovascular Surgery, Saarland University Medical Center, Kirrberger Str, 66421

Homburg/Saar, Germany (E-mail: H-J.Schaefers@uks.eu).

J Thorac Cardiovasc Surg 2021;

$0022-5223 / \$ 36.00$

Copyright (c) 2021 by The American Association for Thoracic Surgery

https://doi.org/10.1016/j.jtcvs.2021.07.045
}

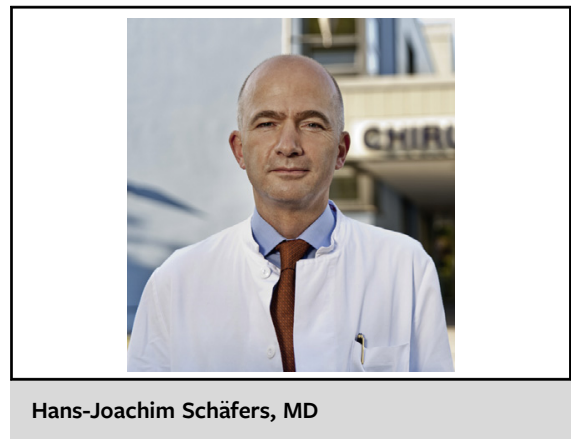

CENTRAL MESSAGE

Direct oral anticoagulant medi-

cations in patients with atrial

fibrillation and bioprosthetic

valves are safe and effective.

is not closely monitored by effect. The results of the metaanalysis thus apply primarily in patients with normal renal function or only mild impairment. In addition, the higher bleeding rates with VKAs have been observed with a target international normalized ratio of 2.0 to 3.0. Because the protective effect of VKA anticoagulation can be observed at lower international normalized ratio values, ${ }^{5}$ further research may be reasonable to better judge the role of VKAs versus DOACs.

\section{References}

1. Mérie C, Køber L, Skov Olsen P, Andersson C, Gislason G, Skov Jensen J, et al. Association of warfarin therapy duration after bioprosthetic aortic valve replacement with risk of mortality, thromboembolic complications, and bleeding. JAMA 2012;308:2118-25.

2. Joint Task Force on the Management of Valvular Heart Disease of the European Society of Cardiology (ESC), European Association for Cardio-Thoracic Surgery (EACTS), Vahanian A, Alfieri O, Andreotti F, Antunes MJ, et al. Guidelines on the management of valvular heart disease (version 2012). Eur Heart J. 2012;33: 2451-96.

3. Otto CM, Nishimura RA, Bonow RO, Carabello BA, Erwin JP III, Gentile F, et al. 2020 ACC/AHA guideline for the management of patients with valvular heart disease: a report of the American College of Cardiology/American Heart Association Joint Committee on clinical practice guidelines. J Thorac Cardiovasc Surg. 2021; 162:e183-353.

4. Yokoyama Y, Briasoulis A, Ueyama H, Mori M, Iwagami M, Misumida N, et al Direct oral anticoagulants versus vitamin $\mathrm{K}$ antagonists in patients with atrial fibrillation and bioprosthetic valves: a meta-analysis. J Thorac Cardiovasc Surg. 2021. XXX:XXX.

5. Odén A, Fahlén M, Hart RG. Optimal INR for prevention of stroke and death in atrial fibrillation: a critical appraisal. Thromb Res. 2006;117:493-9. 